\title{
Blockchain in Academia: Where do we stand and where do we go?
}

\author{
Marinos Themistocleous, Klitos Christodoulou, Elias Iosif, Soulla Louca, Demetrios Tseas \\ Institute For the Future, University of Nicosia \\ \{themistocleous.m, christodoulou.kl, iosif.e, louca.s, tseas.d\}@unic.ac.cy
}

\begin{abstract}
Blockchain is an emerging exponential technology that disrupts the existing way of doing business. During the last 10 years its importance has been highlighted and many organizations worldwide have embraced it and developed innovative applications. Even though Blockchain has been adopted by many sectors, Universities are reluctant to propose new academic programs on this field at bachelor and postgraduate level and fail to efficiently educate students on Blockchain technology and cryptocurrencies. Consequently, universities have failed to investigate the business, technical, legal and other aspects of this technology. As a result, we have the paradox where industry and economy would like to experiment and adopt Blockchain solutions but there is a lack of people with appropriate and adequate skills to work on these solutions. Obviously, this holds back the adoption and the widespread of this technology and currently there are problems in scaling up Blockchain technology. The goal of this paper is to explore the area of Blockchain education and training and propose the structure of a master program that can be used as a model. In doing so, we expand the body of knowledge and we shed light to an important area with limited available information and use cases.
\end{abstract}

Keywords: Blockchain; Bitcoin Education; Understanding Blockchain; Educational Curriculum

\section{Introduction}

Blockchain Technology is a disruptive innovation technology that is expanding at an exponential growth rate. According to Diamandis et al. [1] a disruptive technology is any innovation that creates a new market and it is considered exponential if its growth cycles are characterized by the following framework called the Six $D$ 's of exponentials:

- Digitalization: once a technology could be represented in a digital form (zeros and ones) and becomes an information-based technology.

- Deception: a period in time when an exponential technology passes unnoticed and takes a while to show any visible signs of disruption.

- Disruption: the period where the technology plays a significant role in disrupting various industries.

- Demonetization: this refers to opening up the use of the technology for free, i.e., removing revenue streams from the equation.

- Dematerialization: the technology plays a significant role by itself so that several existing services and products are likely to disappear, replaced or consolidated into something new.

- Democratization: the technology becomes affordable and thus available to anyone to use.

Blockchain technology, firstly instantiated for the settlement of financial transactions, is a relatively new way of developing trust between parties without the need of any intermediaries. The trust implied by Blockchain is built on an underlying peer-to-peer architecture, and protocol rules for building immutable and distributed ledgers in an environment that is maintained by a set of untrusted parties (refer to Section 2.1 for more details). According to the Six D's of exponentials [1], Blockchain technology is deemed disruptive for Finance since it provides an innovative way for money to be represented in a digital form. The solution of the double-spend problem using the idea of time-stamping documents over a decentralized and distributed ledger of transactions can be generalized to the idea of not only transferring value through the Internet, but using it to track information and store data.

Today the ecosystem of Blockchains (or Distributed Ledgers) is evolving rapidly and it has already moved from the growth cycle of deception to the cycle of disruption. Already the emergence of cryptocurrencies 
showed significant evidence of how the technology reaches a stage of demonetization by providing almost zero-fee and instant financial transactions, and signs of dematerialization since crypto-assets and stablecoins are progressively substituting products and services of traditional financial institutions. It is therefore expected that the underlying Blockchain technology represents the second generation of the internet, with "the potential to transform money, business, government and society" [2].

Although Blockchain is considered by the community as the catalyst for innovation that is expected to introduce radical shifts that could drive society to the next industrial evolution, there is a significant gap in Blockchain education and the related Blockchain literacy.

A recent study conducted by HSBC UK [3] revealed that $59 \%$ of the sample of individuals ${ }^{1}$ reported that they had never heard of Blockchain technology. In addition, $80 \%$ of the individuals who have heard of the Blockchain hype reported that they do not understand the technology or how to use it. Another survey conducted by Provoke Insights ${ }^{2}$ on behalf of eToro suggested that $44 \%$ of investors are reluctant with crypto investments and trading due to limited educational resources on the topic. The study further suggested that the lack of education is indeed a major factor for stopping people from actively participating.

The complexity of the underlying technology is one of the factors that introduces a steep learning curve for people that are keen to have a basic understanding of the core technology. Even developers of the technology have concerns that relate to the maturity of the technology, lack of implementation standards or well documentation. Thus, although there is a significant increase for Blockchain developers [4] the available talent lacks far from the optimal numbers.

In view of the significant disruptive nature offered by Blockchain technology, this paper makes the case that adoption and true harnessing of the technology requires Education and Research Institutions to increase their capacity to fill the education gap for Blockchain. Such capacity is critical for ensuring long-term sustainability, and to foster the emergence of research initiatives that could drive the technology to the next level. It is argued that education holds the opportunity to communicate the technology that will spawn overall adoption and evolution of Blockchain and Distributed

\footnotetext{
${ }^{1}$ The sample involved 2000 individuals from the UK, as well as, 1000 consumers from other countries: Canada, China, France, Germany, Hong Kong, India, Mexico, Singapore, the UAE and the US.

${ }^{2}$ Survey was conducted online among 1000 investors, ages from 20 to 65 .
}

Ledger Technologies (DLTs) in general.

To the best of our knowledge, there is a lack of normative literature investigating Blockchain related academic degrees. There is also a confusion in the area as universities add sporadic Blockchain courses into their existing programs and they promote them as Blockchain specific education programs for marketing purposes. To clarify this confusion, we have initiated a research project that aims to explore and analyze Blockchain education at the academic level. The contribution of this paper is twofold: first, it expands the body of knowledge by creating a map with the universities that are active in Blockchain education (especially at postgraduate level), and second it attempts to highlight the main constructs that a Master of Science (MSc) degree should have to address the increase needs in Blockchain education.

The remainder of this paper is structured as follow: Section 2 discusses the background literature and Section 3 presents the challenges in Blockchain education. Thereafter Section 5 introduces the research question and methodology and Section4 presents and analyses the empirical data. The paper concludes in Section 6 where the main conclusions are discussed.

\section{Background}

Blockchains represent one of the most disruptive technological innovations of the last decade. Blockchains can pave the way to groundbreaking research, technology development, and disruptive innovation, igniting the creation of revolutionary business models and markets in a wide number of fields, including financial services, commerce, smart contracts, the Internet of Things (IoT), cyber-security, machine-to-machine transactions and many others.

\subsection{Overview of Blockchain Mechanics}

Blockchains can be defined as distributed ledgers exhibiting high security through the incorporation of cryptographic algorithms. Digital currencies (crypto-currencies) constitute the most successful application of Blockchain technologies. The most popular Blockchain implementation is Bitcoin which includes the homonymous crypto-currency abbreviated as BTC [5]. Blockchain transactions are conducted through digital addresses. For the case of crypto-currencies, the most common transaction is to transfer such currencies from one (or more) address(es) to other address(es). This flow can be generalized to any form of digital assets. One of the key functions of Blockchains is the recording of those transactions on the underlying chain of blocks that are maintained by 
the nodes of the network. In general, a Blockchain can be implemented as a data structure that guarantees the immutability of the respective data. Identical copies of this structure exist in each node of the network. A subset of these nodes has a special operational role: the aggregation of chunks of transactions into blocks and the transmission of those blocks into the network for being appended to the chain of blocks. The append operation is allowed under some well-defined conditions. Specifically, a consensus should be reached among the nodes. Various consensus mechanisms have been proposed in the literature, e.g., the proof-of-work mechanism is utilized in the context of the Bitcoin protocol.

The basic idea behind the consensus mechanisms is to identify any invalid transaction and prohibit the addition of the corresponding blocks into the Blockchain. Under sufficiently secure consensus, the blocks can be considered to be corruption- and tamper-proof. A special dimension of this aspect that has attracted great research interest is the study of the conditions under which malicious nodes can take control of the network and alter the validity of the transactions/blocks $[6,7,8]$. It is importnant since the sustainability of the network relies on the hypothesis that the involved nodes behave rationally, i.e., try to maximize their benefits. The incentivization of the rational operation is adopted by a number of Blockchains including Bitcoin. Specifically, a small amount of transaction fees are paid to the nodes that successfully manage to append new blocks to the chain.

Table 1 provides a high-level overview of the major Blockchains (e.g., Bitcoin, Ethereum, Hyperledger Fabric) with respect to a number of technical characteristics.

\subsection{Use cases: Beyond Crypto-currencies}

The ability of Blockchains to track transactions in an atomic level makes their deployment desirable when an asset is transferred as they can keep track of the assets movements (e.g., see [9]). While the asset is transferred from point $\mathrm{A}$ to point $\mathrm{B}$, there might be several intermediate points in between. It is of ultimate importance that the asset is not tampered with, diverted, or modified in any way without prior permission. In the next paragraphs, a number of indicative use cases are briefly described.

In the agricultural sector, Blockchain technologies can influence three key areas. First, consumers demand quality fresh food but producers and manufacturers are having a hard time verifying the accuracy of data from farm to table. The ability of Blockchain to make the supply chain entirely transparent and rich with immutable provenance data from farm to table assists in providing solutions to this problem. Second, Blockchains have the potential to create and improve access to financial services in the developing world through mobile payments, credits, and decreased transaction fees. Over a billion people worldwide dealing with agriculture, many of whom are smallholder farmers in developing countries are in need of capital. Third, Blockchains enable trustworthy, efficient supply chains in the developing world as they can improve they can improve the settlement process for farmers, buyers, and financial institutions like banks. Adding transparency, trust, and efficiency to settlements can decrease risk and unlock new financing mechanisms for banks [10].

IoT is a fast-growing industry destined to transform homes, cities, farms, factories, the consumers and the enterprise space. According to Gartner ${ }^{3}$, by 2020, there will be more than 20 billion connected devices across the globe, powering a market that will be worth over 3 trillion USD. This frenzied growth of IoT is introducing several challenges, including identifying, connecting, securing, and managing the connected devices [11]. A vast majority of IoT platforms are based on a centralized model in which an agent or hub controls the interaction between devices. Supporting these large IoT ecosystems with such infrastructures is very challenging and not practical in cases in which devices need to exchange data autonomously [12]. Blockchains enable the implementation of decentralized platforms that facilitate the distribution of data securely and transparently via a peer-to-peer model [13].

In the energy sector, the integration of IoT with Blockchains allows for a peer-to-peer market where machines can buy and sell energy automatically, according to user-defined criteria [13]. Producers of renewable energy usually use the energy they produce to cover their own needs and any excess energy is then fed into the grid along with the necessary data on the production from the meters of the prosumers. This information is then used to determine the rates at which prosumers are rewarded for their produced energy and consumers are billed for their withdrawn energy. These rates (or functions) are designed to incentivize agents to balance supply and demand, as well as, lower production and consumption peaks [14].

\subsection{Adoption Barriers}

Despite the excellent technological properties of Blockchains, a low adoption degree exists. A

\footnotetext{
${ }^{3}$ http://www.gartner.com/newsroom/id/3165317
} 


\begin{tabular}{|c|c||c|c|}
\cline { 2 - 4 } \multicolumn{1}{c|}{} & Bitcoin & Ethereum & Hyperledger Fabric \\
\hline \hline Blockchain type & Public & Public & Private \\
\hline Consensus mechanism & Proof-of-Work & Hybrid, towards PoS & Pluggable Kafka (default) \\
\hline Native currency & Bitcoin (BTC) & Ether (ETH) & No \\
\hline Programming language & Bitcoin script & Solidity & Java, Go, Nodejs, Javascript \\
\hline Smart contracts & No & Yes & Yes \\
\hline Read access & Public & Public & Private \\
\hline Write access & Public & Public & Private \\
\hline
\end{tabular}

Table 1. Overview of major Blockchains with respect to various technical characteristics

detailed study is reported in [15], where a series of possible reasons were identified as follows: (i) Not well-established regulations; (ii) Risks regarding confidentiality; (iii) Difficulties in updating traditional business practices; (iv) Technological immaturity; (v) Business networking challenges; (vi) Data protection related risks; (vii) Uncertainty about scalability and performance; (viii) Unwillingness to relax the centralized control; (ix) Potential security risks; (x) Uncertainty about the possible benefits as opposed to the respective cost; (xi) Not clear use cases.

The aforementioned reasons can be clustered into three broad thematic categories: (i) regulatory, (ii) business, and (iii) technological. In these categories, the concepts of "uncertainty" and "risk" are noticeable. Under such conditions we suggest that Blockchain education can bridge the gap between uncertainty and harnessing the true potential of the technology, with the ultimate goal of driving mass adoption. To further elaborate, we view education as the main driver to spreading adoption of the technology that emerges from educating the masses to the possibilities of the technology. Due to the complexity of the technology there is a need of well-structured educational programs that provide a combination of skills combined with theory. In subsequent sections we articulate on the multi-disciplinary character that such educational programs should hold and we discuss the status of Blockchain education in academia.

\subsection{Lowering the Adoption Barriers}

Overall, the significance of Blockchain technologies is well beyond the area of crypto-currencies. Blockchains, as a secure data structure, can be applied to any data-centric application layer that requires no central authority for validating the data of interest. Despite the aforementioned barriers for adoption, the implications for research in the area of Blockchains is becoming clear with respect to various sectors (e.g., financial services, supply chain, healthcare). For academia, the challenge is to adopt a holistic perspective in an attempt to coordinate inter-disciplinary educational and research efforts. This is not a trivial case since carefully designed programmes are required that often host heterogenous audiences. In any case, we argue that the up-to-date education (including professional training) constitutes the primary vehicle for alleviating any concerns about the latest technological advances. Towards this goal, a number of challenges should be addressed, as discussed in subsequent sections.

\section{Challenges in Education}

The social and economical dividends of Blockchain technologies appear to be boundless with the potential to contribute in achieving significant economic, and social benefits. Recent and projected developments in the fields of Blockchains are revolutionizing our society and our economy becoming also an increasingly influential factor in education.

Training for jobs to be invented. As the communications revolution is shrinking the world to our mobile devices for access anytime anywhere, the transition to a new Economy has also began, with Blockchains playing a key role. For embracing the new economy, connectivity and digital skills are requirements. If our challenge could be limited to preparing people for the kinds of jobs available today, we would still have a lot of work to do. Unfortunately, the challenge is even greater. Many of the jobs that will be available in the future have yet to be invented.

Skills mandatory for everybody. At the same time, these students living in a complex information intensive society must have the capabilities and the competencies to operate effectively in that society. One must be able to access the right information quickly, process it and effectively use it and communicate it in various formats - a skill known as information literacy. Information literacy is a prerequisite for participative citizenship, social inclusion, the creation of new knowledge, personal empowerment and learning for life [16]. One important aspect of information 


\begin{tabular}{|c|c|c|c|}
\hline University & Country & Level & Course \\
\hline Fundao Getlio Vargas (FGV) & Brazil & Postgraduate & MA Crypto-Finance \\
\hline University of British Columbia & Canada & Postgraduate & Announced - Blockchain Training Path \\
\hline University of Nicosia (UNIC) & Cyprus & Postgraduate & MSc in Digital Currency \\
\hline Montpellier Business School & France & Postgraduate & $\begin{array}{l}\text { MSc in Innovative Finance - Fintech, } \\
\text { Blockchains and Cryptocurrencies }\end{array}$ \\
\hline $\begin{array}{lll}\text { Dublin } & \text { City } & \text { University }\end{array}$ & Ireland & Postgraduate & MSc in Blockchain - Distributed Ledger \\
\hline $\begin{array}{l}\& \text { Technology Ireland ICT } \\
\text { Skillnet }\end{array}$ & & & Technologies \\
\hline $\begin{array}{l}\text { Universit degli Studi }- \text { Link } \\
\text { Campus University }\end{array}$ & Italy & Postgraduate & $\begin{array}{l}\text { MBA in Blockchain and Economics of } \\
\text { Cryptocurrencies }\end{array}$ \\
\hline Universit ta Malta & Malta & Postgraduate & $\begin{array}{l}\text { MSc in Blockchain and Distributed Ledger } \\
\text { Technologies (Business and Finance) }\end{array}$ \\
\hline $\begin{array}{l}\text { Leadership \& } \quad \text { Management } \\
\text { Institute }\end{array}$ & Malta & Postgraduate & MSc in Blockchain and Cryptocurrency \\
\hline $\begin{array}{l}\text { Moscow Institute of Physics and } \\
\text { Technology (MIPT) }\end{array}$ & Russia & Postgraduate & Master Program Blockchain \\
\hline IL3 Universitat de Barcelona & Spain & Postgraduate & $\begin{array}{l}\text { Global Master's in Blockchain } \\
\text { Technologies }\end{array}$ \\
\hline Universidad Catlica de Murcia & Spain & Postgraduate & MBA in Blockchain Management \\
\hline EADA - Business School Barcelona & Spain & Postgraduate & $\begin{array}{l}\text { Blockchain, DLT Technologies and } \\
\text { Cryptoeconomics }\end{array}$ \\
\hline University of Girona & Spain & Postgraduate & $\begin{array}{l}\text { MSc in Distributed Ledger and Artificial } \\
\text { Intelligence }\end{array}$ \\
\hline Universidad Europea de Madrid & Spain & Postgraduate & Diploma in Blockchain \\
\hline $\begin{array}{l}\text { EU Business School + University of } \\
\text { Roehampton UK }\end{array}$ & UK & Postgraduate & $\begin{array}{l}\text { MSc in International Management or } \\
\text { MBA (EU Business school certificate } \\
\text { of Advance studies in Blockchain } \\
\text { management.) }\end{array}$ \\
\hline Northeastern University & USA & Postgraduate & 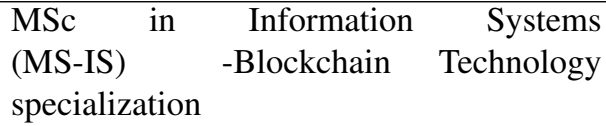 \\
\hline University of the Cumberlands & USA & Postgraduate & $\begin{array}{l}\text { MS Global Business with Blockchain } \\
\text { Technology }\end{array}$ \\
\hline
\end{tabular}

Table 2. Universities offering postgraduate degrees

literacy is the digital skills that prepare students for jobs that have yet to be invented. The educational process should be focusing around this concept. In order to thrive in such a fast-paced world of constant change, the skills needed to become lifelong learners must be imparted to all our students.

Access. As technology advances and the old technologies are being replaced by new ones, these technologies will not be accessible to everyone. The very technology that has the power to empower us all also has the potential to increase the problems of social exclusion. Digital inequality has taken the form of social inequality. As Blockchain technologies have become a new source of economic growth, there is indeed cause for concern that Blockchains could become a factor contributing to the widening of income differentials between countries. Domestic digital divides often mirror existing inequities within developing and developed countries and are therefore likely to reinforce them rather than contribute to developmental objectives.

\section{Research Questions and Methodology}

We are at the beginning of a global wave of demand for Blockchain academic and professional education. According to Forbes [17] there was a huge growth of the demand for Blockchain by $6000 \%$ in 2018. In addition to this, Bloomberg reported that cryptocurrencies and Blockchain are the faster growing skills online. Statistics show that the Blockchain market will be worth $23.3 \mathrm{~B}$ by 2023 from $1.2 \mathrm{~B}$ in 


\begin{tabular}{|l|l|}
\hline Academic Institution & \# Courses Offered \\
\hline University of Nicosia (UNIC) & 18 \\
\hline Cornell University & 24 \\
\hline Duke University & 3 \\
\hline Georgetown University & 1 \\
\hline Massachusetts Institute of Technology (MIT) & 6 \\
\hline Princeton University & 9 \\
\hline Stanford University & 17 \\
\hline University of California - Berkeley & 9 \\
\hline Royal Melbourne University (RMIT) & $1^{*}$ \\
\hline New York University (NYU) & 5 \\
\hline University of Illinois at Urbana-Champaign & $1^{*}$ \\
\hline University of Pennsylvania & 6 \\
\hline National University of Singapore & 5 \\
\hline University of California - Los Angeles (UCLA) & 3 \\
\hline Swiss Federal Institute of Technology Zurich & 3 \\
\hline Harvard University & 7 \\
\hline University of Texas Austin & 2 \\
\hline Johns Hopkins University & 1 \\
\hline Columbia University & 5 \\
\hline Yale University & 3 \\
\hline University of Chicago & 2 \\
\hline University of Cumbria & $1^{*}$ \\
\hline IT University of Copenhagen & $1^{*}$ \\
\hline George Mason University & 1 \\
\hline UCL Centre for Blockchain Technologies (CBT) & $1^{*}$ \\
\hline University of North Carolina & 1 \\
\hline University of Oxford & $1^{*}$ \\
\hline University of Louisville - IBM Academy & $1^{*}$ \\
\hline University of Copenhagen & $1^{*}$ \\
\hline University of Pittsburgh & $1^{*}$ \\
\hline University of Sydney & $1^{*}$ \\
\hline University of Edinburgh & $1^{*}$ \\
\hline ETH Zurich & $1^{*}$ \\
\hline Canadian University /Dubai & 2 \\
\hline Universitad Europea Madrid & $1^{*}$ \\
\hline University of Waterloo & $1^{*}$ \\
\hline University of Stirling & $1^{*}$ \\
\hline University of Cape Town & 1 \\
\hline Carnegie Mellon University & 3 \\
\hline
\end{tabular}

Table 3. Universities offering Blockchain courses - *Indicates Universities that offer various courses through Blockchain training, academies, summer schools and others

2018 [18]. On the contrary, the academic community, with a small number of exemptions, has not considered the Blockchain technology and has not yet formulated degree programs with which it will educate students in this new technology. Students request specialized academic degrees on Blockchain but currently there is limited number of such degrees available.

This paper attempts to investigate this area and in do so is focusing on the following research questions (RQ):

RQ1: What is the current status of Blockchain academic education?

RQ2: What are the constructs of a Blockchain Master of Science $(\mathrm{MSc})$ degree?

In order to investigate the research questions, 
we adopted different approaches and techniques that include:

- a web research to scan the academic market using specific keywords like "blockchain MSc", "blockchain MBA management", "blockchain courses in universities", "cryptocurrency courses in universities", "blockchain academic degree", "cryptocurrency academic degree" etc.

- an exploratory qualitative study to collect and analyze data from the 1st university that launched an MSc in Digital Currency and Blockchain (University of Nicosia - UNIC), and

- a survey with the UNIC alumni to analyze their views regarding the program structure, career prospects, employability, etc.

We choose to collect data from the University of Nicosia and its alumni as it is the first known University to offer an MSc on Blockchain and cryptocurrencies and has also a significant number of graduates.

\section{Empirical Data and Analysis}

During the first phase of our research we collected data from the Internet using the set of search keywords reported in the previous section. The aim was to scan the global academic market and identify those universities that offer degrees at either undergraduate or graduate level on Blockchain technology and/or cryptocurrencies. Some of the keywords we used returned results that show many courses on Blockchain that are offered by universities. On further investigating these results, we found out that many of them are not academic courses but professional courses developed by universities like MIT, LSE, Oxford, Stanford, UNIC etc that are delivered through online professional training platforms such as Udemy, Edx, Coursera, GetSmarter or other proprietary professional training platforms (e.g., UNIC). There are also several universities that offers courses on Blockchain, but these are incorporated to existing academic programs (e.g., Blockchain course at MSc Digital Systems at University of Piraeus, Greece).

The results as presented in Table 2.4 illustrate that today there are 17 universities around the globe that have announced or run degrees on Blockchain. From 2014 to 2018, the only university that offered an MSc on this area was UNIC. In 2018, we observed a new wave of accredited programs from other universities, and in 2019 we recorded that there are 17 universities in total, more specifically, Brazil (1), Cyprus (1), Canada (1), France (1), Ireland (1), Italy (1), Malta (2), Russia (1), Spain (5), UK (1) and USA (2) that offer or announced their plans for Blockchain degrees. Clearly this demonstrates a significant change compared to the previous years in the number of universities that are exploring the technology moving towards Blockchain education. It also illustrates a small and slow response to the demand for Blockchain academic degrees. It is worth noting that all 17 degrees on Blockchain are at the postgraduate level which again shows that the goal is to offer specialized programs that respond to the disruptive nature of Blockchain.

In order to further investigate the area under research, we studied the practices of UNIC based in Cyprus that was the first university to recognize the educational gap on Blockchains and responded by offering the first Master of Science degree in Blockchain education in 2014. In 2012, UNIC recognized the need for Blockchain degrees, and before launching its MSc degree in Digital Currency (cryptocurrencies) and Blockchain it decided to become a cryptocurrency friendly University. In doing so, in 2013, it became the first university to allow students to pay tuition fees using Bitcoin. This had a positive response and soon many students started paying their fees in Bitcoin and several professors/instructors received their payments in Bitcoin too.

In the beginning of 2014, the UNIC launched the first Master of Science degree (MSc) in Digital Currency. The Master is delivered online and students tune in to attend the online live streaming sessions on set weekly dates and participate in online discussions, while flexibly gaining access to course materials in their own schedules, including weekly quizzes with a set date for the final exam.

The MSc in Digital Currency consists of 15 courses. The workload per course for the 13 of these courses is 10 ECTS and for the remaining two courses (MSc thesis and MSc project) is 20 ECTS. The students are required to successfully complete 90 ECTS for the degree to be awarded. Six out of the 15 courses are required courses and nine are electives courses. Students can select electives of 30 ECTS in total. They can either select to attend three electives courses of 10 ECTS each or undertake a Master thesis (project) for 20 ECTS and select also one elective course of 10 ECTS. Table 4 below presents the current structure of the MSc in Digital Currency and blockchain.

The MSc in Digital Currency and blockchain commenced with a free introductory Massive Open Online Course (MOOC) taught by the Bitcoin evangelist and best seller author Andreas Antonopoulos [19, 20] and the CEO of the University of Nicosia Antonis Polemitis. The MOOC course focuses on cryptocurrencies and Blockchain, has run 11 times in 


\begin{tabular}{|l|l|l|}
\hline \multicolumn{2}{|l|}{ PROGRAM STRUCTURE } & ECTS \\
\hline Section A Required Courses & Min. ECTS Credits: 60 \\
\hline BLCK-511 & Introduction to Digital Currencies & 10 \\
\hline BLCK-512 & Money and Banking & 10 \\
\hline BLCK-513 & Open Financial Systems & 10 \\
\hline BLCK-522 & Regulation and Digital Currencies & 10 \\
\hline BLCK-523 & Principles of Disruptive Innovation & 10 \\
\hline BLCK-524 & Blockchain Technology \& Applications & 10 \\
\hline Section B Electives not requiring programming background & Min. ECTS Credits: 30 \\
\hline BLCK-521 & International Currency Markets & 10 \\
\hline BLCK-534 & Financial Markets and Alternative Investments & 10 \\
\hline BLCK-535 & Digital Currencies in the Developing World & 10 \\
\hline BLCK-536 & Emerging Topics and Practical Considerations in Blockchains & 10 \\
\hline BLCK-591 & Thesis Option & 20 \\
\hline BLCK-592 & Project Option & 20 \\
\hline Section B Electives requiring programming background & Min. ECTS Credits: 30 \\
\hline BLCK-530 & Cryptographic Systems Security & 10 \\
\hline BLCK-541 & Digital Currency Programming & 10 \\
\hline BLCK-545 & Programming on the Blockchain & 10 \\
\hline
\end{tabular}

Table 4. Program Structure of the MSc in Digital Currency offered by UNIC

a row since 2014 , and more than 30,000 participants from 95 countries have attended it so far. Most of the MOOC students do not continue their studies in the MSc as their goal is to get a very good knowledge of the basics of cryptocurrencies and Blockchain. The remaining MOOC students can continue their studies and complete the MSc or they can select a subset of the MSc to study and get a certificate. UNIC offers three Blockchain certificate programs namely: (i) Blockchain Financial Analyst (ii) Blockchain Business Analyst (iii) Blockchain Developer.

Each of these certificate programs includes a subset of the MSc courses. For instance, to become a certificate Blockchain developer a student must successfully attend the courses: (i) Blockchain Technology and Applications (ii) Cryptographic Systems Security (iii) Digital Currency Programming (iv) Programming on the Blockchain.

The MSc in Digital Currency has been successful and has significantly improved the level of understanding of the participants and had been beneficial for them. There are a lot of success stories of the MSc participants that worth reporting but the most known one is the case of Tey El-Rjula. The war in Syria, in 2014, led him to a refugee camp. While at the camp he enrolled for the free MOOC at UNIC and he soon earned his certificate on cryptocurrencies and Blockchain. In 2017, with a scholarship from UNIC he earned his MSc in Blockchain. Today he runs his own Blockchain startup company in Amsterdam and is rewriting his own story. For the purpose of this research we contacted the alumni of the MSc in Digital Currency at UNIC and we asked them about the quality of the MSc program, their employability, the changes in their career and employability prospects. We received responses from 147 alumni and from those we accepted only 116 answers as 31 questionnaires were not fully completed. Recorded data from their testimonies are presented in Table 5.

The empirical data indicate that the distribution of the courses of the MSc program in Digital Currency and blockchain is within the right direction as it has a good balance regarding business, regulatory and technical courses. Although the students are satisfied with the current structure of the MSc, they suggested the addition of new courses that can help them to further focus on the concentration they like. More than the one quarter of the responders requested the addition of more technical courses as many of them have a technical profession. The addition of courses in the areas of business and regulations was also suggested by smaller number of alumni.

It appears that the MSc in Digital Currency had a great impact on the employability of the its graduates. The empirical data show that more than $50 \%$ of the graduates found a Blockchain related profession either within the same employer or in a different one. The data also reveal that from the $63 \%$, who decided to change their occupation, the $86 \%$ of them found a Blockchain related job. The rest $14 \%$ did not want to move to Blockchain area. It is worth noting that the MSc helped the students to coin their own business idea and come 


\begin{tabular}{|l|l|}
\hline Question & Respond \\
\hline How do you rate the quality of the & $92 \%$ excellent \\
MSc program & $8 \%$ very good \\
\hline & $58 \%$ No changes \\
Suggestions to improve the MSc & $27 \%$ add more technical courses \\
program & $4 \%$ add more regulation courses \\
& $2 \%$ add more business courses \\
\hline Are you satisfied with the quality & $92 \%$ Yes \\
of the online delivery mode & $8 \%$ No I prefer the traditional mode \\
\hline Problems encountered & $82 \%$ No problem \\
& $18 \%$ problems to attend live sessions due to time zone difference \\
\hline & $16 \%$ Blockchain developer \\
& $11 \%$ Blockchain startupper \\
& $11 \%$ Blockchain advisors and consultants \\
& $10 \%$ Blockchain analyst \\
Current profession & $10 \%$ Blockchain quality engineer \\
& $8 \%$ Blockchain legal consultant \\
& $3 \%$ Blockchain system architect \\
& $3 \%$ Blockchain researcher / PhD students \\
& $2 \%$ Cryptocurrency trader \\
& $26 \%$ Other \\
\hline Changes in the profession since & $37 \%$ Same profession \\
the beginning of MSc in Digital & $54 \%$ New - blockchain related profession \\
Currency and blockchain & $9 \%$ New other \\
\hline
\end{tabular}

Table 5. Results from the alumni survey for the MSc in Digital Currency

out with the establishment of their own startup. The example of Tey reported above is one of the many that exists. Other examples demonstrating how the MSc helped its students to progress their career are those of Bryan and Marcella, among others. Bryant Joseph Gilot used to be a medical doctor in Philadelphia (USA) and after earning his Blockchain MSc from UNIC he became the chief medical officer at Blockchain Health co. in San Francisco. Marcella Atzori who now works as analyst and researcher at University College London reported:

"I am the first woman in the world to earn this degree and I am so proud of it. It enabled me to acquire the necessary technical expertise for carrying out my research on Blockchain, governance and public policy. It has been a valuable opportunity for professional growth."

From the data analysis we come out to the following findings regarding to RQ1:

The Leader. Historical and empirical data reveal that UNIC is the world leader in this category. It launched its MSc since 2014 and in 2016 it had the first graduates of its program. So far more than 30,000 attended the MOOC course of this MSc and more than 600 students have enrolled for the MSc.

Early adopters. Early adopters are those universities that are moving to the development of an MSc on Blockchain or have announced their MSc or have recently launched it like the universities of Barcelona, Malta.

Early majority. Many universities updated their MSc and BSc programs to offer Blockchain related courses (see Table 3). It appears that these universities are currently experimenting with these degrees and they are more likely to offer MSc programs in the future.

In terms of undergraduate studies, there are no moves in the space expect independent courses on Blockchain and Cryptocurrencies. We estimate that it will be difficult to offer a whole BSc on Blockchain as this technology requires a high level of specialization which is more appropriate for postgraduate degrees. In regard to the second research question it appears that an 
MSc on Blockchain may include courses in areas such business, software engineering and regulation. Due to the disruptive nature of Blockchain, graduates should have a multidiscipline understanding of this area in order to be able to increase their performance.

\section{Conclusions}

Blockchain is a disruptive exponential technology that affects most of the sectors of the economy. To scale up Blockchain, we need to focus on the adoption, regulation and sourcing. With education and training we increase awareness and adoption. With regulation we set up the framework on how to build and run Blockchain applications and how to operate in this space. Education on Blockchain, law, regulation and policy is also important as it helps to better understand the rules of the Blockchain game. Blockchain companies need specialists (Blockchain developers, analysts, engineers, regulators, consultants etc.) to help them grow and thus, education on Blockchain helps companies to address their sourcing problems.

In this paper, we focus on two research questions to investigate the current status of Blockchain in academic education and to attempt to understand what the main constructs of a Blockchain MSc degree are. To investigate our research questions, we used a mixed methodology and we found out that Blockchain education is still in its infancy. There are universities and other institutions that have incorporated courses to their existing programs and most of them are on the basics of Blockchain technology. There is also a small number of 17 universities that have recently launched or announced their postgraduate programs on Blockchain. The first move in that area was in 2014 and the rest the last two years. Data collected for our analysis focused on the first university that launched an MSc degree on Blockchain. The alumni of this MSc degree where also conducted so that we could get their personal perspectives for the purposes of our studies. The results showed that the specific MSc was highly beneficial for its graduates and help them to move the career ahead. The analysis of the data demonstrates that an MSc on this topic should have Blockchain courses focusing on technical, business and regulations.

Further research on this topic is required and we are currently analyzing data to offer an in-depth analysis of the different programs that exist today.

\section{References}

[1] P. H. Diamandis and S. Kotler, Bold: How to go big, create wealth and impact the world. Simon and Schuster, 2015.
[2] D. Tapscott and A. Tapscott, Blockchain revolution: how the technology behind bitcoin is changing money, business, and the world. Penguin, 2016.

[3] H. H. plc, May 2017. [Online; posted 17-May-2017].

[4] U. G. Inc., "Quarterle skills index - the top20 fastest growing skills," 2018. [Online; posted Q1-2018].

[5] S. Nakamoto, "Bitcoin: A peer-to-peer electronic cash system," 2008.

[6] C. Badertscher, U. Maurer, D. Tschudi, and V. Zikas, "Bitcoin as a transaction ledger: A composable treatment," in Annual International Cryptology Conference, pp. 324-356, Springer, 2017.

[7] J. Garay, A. Kiayias, and N. Leonardos, "The bitcoin backbone protocol: Analysis and applications," in Annual International Conference on the Theory and Applications of Cryptographic Techniques, pp. 281-310, Springer, 2015.

[8] A. Kosba, A. Miller, E. Shi, Z. Wen, and C. Papamanthou, "Hawk: The blockchain model of cryptography and privacy-preserving smart contracts," in 2016 IEEE symposium on security and privacy (SP), pp. 839-858, IEEE, 2016.

[9] K. Korpela, J. Hallikas, and T. Dahlberg, "Digital supply chain transformation toward blockchain integration," in proceedings of the 50th Hawaii international conference on system sciences, 2017.

[10] E. Weston and S. Nolen, "From bitcoin to agriculture: how can farmers benefit from blockchains," 2016.

[11] B. Dickson, "How blockchain can change the internet of things." https: //venturebeat.com/2016/11/20/ how-blockchain-can-change-the-future-of-iot/, 2016.

[12] M. Crosby, P. Pattanayak, S. Verma, V. Kalyanaraman, et al., "Blockchain technology: Beyond bitcoin," Applied Innovation, vol. 2, no. 6-10, p. 71, 2016.

[13] K. Christidis and M. Devetsikiotis, "Blockchains and smart contracts for the internet of things," Ieee Access, vol. 4, pp. 2292-2303, 2016.

[14] M. Mihaylov, S. Jurado, K. Van Moffaert, N. Avellana, and A. Nowe, "Nrg-X-change-a novel mechanism for trading of renewable energy in smart grids.," in Smartgreens, pp. 101-106, 2014.

[15] G. Hileman and M. Rauchs, "Global cryptocurrency benchmarking study," Cambridge Centre for Alternative Finance, vol. 33, 2017.

[16] A. Bundy, "One essential direction: information literacy, information technology fluency," Journal of eLiteracy, vol. 1, no. 1, pp. 7-22, 2004.

[17] L. Mearian, "Blockchain moves into top spot for hottest job skills." https: / / bit. Iy/2WRCVWM, May 2018.

[18] MarketsandMarkets, "Blockchain market worth $\$ 23.3$ billion by 2023." https://prn.to/2WKMeaX, Dec 2018.

[19] A. M. Antonopoulos, Mastering Bitcoin: Programming the open blockchain. " O'Reilly Media, Inc.", 2017.

[20] A. M. Antonopoulos and G. Wood, Mastering ethereum: building smart contracts and dapps. O'Reilly Media, 2018. 